\title{
Existence and multiplicity of periodic solutions and subharmonic solutions for a class of elliptic equations
}

\section{Xiujuan Wang, Aixia Qian*}

School of Mathematical Sciences, Qufu Normal University, Shandong 273165, P. R. China.

\section{Abstract}

This paper focuses on the following elliptic equation

$$
\left\{\begin{array}{l}
-\mathfrak{u}^{\prime \prime}-\mathfrak{p}(x) \mathfrak{u}=f(x, \mathfrak{u}), \quad \text { a.e. } \quad x \in[0, l], \\
\mathfrak{u}(0)-\mathfrak{u}(l)=\mathfrak{u}^{\prime}(0)-\mathfrak{u}^{\prime}(l)=0,
\end{array}\right.
$$

where the primitive function of $f(x, u)$ is either superquadratic or asymptotically quadratic as $|u| \rightarrow \infty$, or subquadratic as $|u| \rightarrow 0$. By using variational method, e.g. the local linking theorem, fountain theorem, and the generalized mountain pass theorem, we establish the existence and multiplicity results for the periodic solution and subharmonic solution. (C)2017 All rights reserved.

Keywords: Elliptic equation, periodic solution, superquadratic, subquadratic, asymptotically quadratic, subharmonic solution. 2010 MSC: 35J25, 35J20, 35J60, 35J61.

\section{Introduction and main results}

In this paper, we consider the following elliptic equation

$$
\left\{\begin{array}{l}
-u^{\prime \prime}-p(x) u=f(x, u), \quad \text { a.e. } \quad x \in[0, l], \\
u(0)-u(l)=u^{\prime}(0)-u^{\prime}(l)=0,
\end{array}\right.
$$

where $0<l<\infty, p(x)$ is continuous, and $F(x, u)=\int_{0}^{u} f(x, s) d s:[0, l] \times \mathbb{R} \rightarrow \mathbb{R}$ is l-periodic in $x$ for all $u \in \mathbb{R}$ and satisfies the following assumption.

(A) $F(x, u)$ is measurable in $x$ for each $u \in \mathbb{R}$ and there exist $a \in C\left(\mathbb{R}^{+}, \mathbb{R}^{+}\right), b \in L^{1}\left(0, l ; \mathbb{R}^{+}\right)$such that

$$
|F(x, u)| \leqslant a(|u|) b(x), \quad|f(x, u)| \leqslant a(|u|) b(x)
$$

for all $u \in \mathbb{R}$ and a.e. $x \in[0, l]$.

In the past, a series of existence results for periodic solution have been obtained in the literatures (see $[1,2,8,13,20,21]$ and their references). But the widely used tool is either the various fixed point theorem or cone theory.

\footnotetext{
*Corresponding author

Email addresses: 1140934106@qq.com (Xiujuan Wang), qaixia@amss.ac.cn (Aixia Qian)
} 
In recent years, however, many scholars have tried to use variational method to get the best result for simple elliptic equation. Nevertheless, to the best of our knowledge, there are few such results. In [7], Liu and Zhao considered the impulsive boundary value problem with small non-autonomous perturbations. They showed the existence of three distinct classical solutions via variational methods and the three critical point theorem. But their works did not identify that the solutions which they obtained are periodic or subharmonic. This has motivated our interest in the topic.

As is known to all, there are many results on periodic solutions and subharmonic solutions for classical Hamiltonian systems. In [4], Li et al. considered the second order Hamiltonian system

$$
\left\{\begin{array}{l}
\ddot{u}(t)+B(t) u(t)+\nabla F(t, u(t))=0, \quad \text { a.e. } t \in[0, T], \\
u(0)-u(T)=\dot{u}(0)-\dot{u}(T)=0,
\end{array}\right.
$$

where $B(t)$ is an $N \times N$ symmetric matrix, continuous and T-periodic in $t ; F: \mathbb{R} \times \mathbb{R}^{N} \rightarrow \mathbb{R}$ is T-periodic $(T>0)$ in $t$ and satisfies the following.

$\left(\mathrm{F}_{0}\right)$ There exist constants $\mathrm{a}_{0}>0$ and $\mathrm{L}_{1}>0$, such that

$$
\langle\nabla F(t, u), u\rangle-2 F(t, u) \geqslant \frac{a_{0}}{|u|^{2}} F(t, u)
$$

for all $u \in \mathbb{R}^{N}$, with $|u| \geqslant L_{1}$ and a.e. $t \in[0, T]$.

In [4], the conditions $\left(\mathrm{F}_{0}\right)$ and $(\mathrm{A})$ are used to prove the $\mathrm{C}$ condition. Nevertheless, Tang and $\mathrm{Wu}$ [19] proved $(\mathrm{C})^{*}$ condition by $\left(\mathrm{F}_{0}\right),(\mathrm{A})$, and the following condition

$$
\lim _{|\mathfrak{u}| \rightarrow 0} \frac{F(t, u)}{|\mathfrak{u}|^{2}}=+\infty \quad \text { uniformly for } \quad \text { a.e. } t \in[0, T] .
$$

Clearly, we can use the method introduced in [4] to prove the $(C)^{*}$ condition without (1.3).

Over the last few years, many researchers studied the existence of periodic solutions for problem (1.2) under the following condition.

$\left(\mathrm{F}_{0}^{\prime}\right)$ Assume that there exist $\lambda>2$ and $\beta>\lambda-2$ such that

$$
\begin{array}{r}
\limsup _{|\mathfrak{u}| \rightarrow \infty} \frac{F(x, u)}{|u|^{\lambda}}<\infty \text { uniformly for a.e. } x \in[0, T], \\
\liminf _{|u| \rightarrow \infty} \frac{\langle\nabla F(x, u), u\rangle-2 F(x, u)}{|u|^{\beta}}>0 \text { uniformly for a.e. } x \in[0, T] .
\end{array}
$$

Obviously, $\left(\mathrm{F}_{0}\right)$ is weaker than $\left(\mathrm{F}_{0}^{\prime}\right)$. Hence, we will replace $\left(\mathrm{F}_{0}^{\prime}\right)$ by $\left(\mathrm{F}_{0}\right)$.

For more papers on periodic solutions and subharmonic solutions for classical Hamiltonian systems (1.2), please see $[5,9,22-24]$ and their references. Inspired by those works mentioned above, we study periodic solutions and subharmonic solutions problems for the elliptic equation (1.1).

\subsection{Periodic solutions of elliptic equation}

In this section, we deal with the existence and multiplicity of l-periodic solution of problem (1.1) under the assumption: $p(x)$ is l-periodic in $x$.

We will divide the problem into three cases.

\subsubsection{The superquadratic case}

For the superquadratic case, we make the following assumptions

$\left(F_{1}\right) \lim _{|\mathfrak{u}| \rightarrow 0} \frac{F(x, \mathfrak{u})}{|\mathfrak{u}|^{2}}=0$ uniformly for a.e. $x \in[0, l]$.

$\left(F_{2}\right) \lim _{|\mathfrak{u}| \rightarrow \infty} \frac{F(x, \mathfrak{u})}{|\mathfrak{u}|^{2}}=+\infty$ uniformly for a.e. $x \in[0, \mathfrak{l}]$. 
$\left(\mathrm{F}_{3}\right)$ There exist constants $\mathrm{a}_{0}, \mathrm{~L}_{1}>0$, such that

$$
\langle f(x, u), u\rangle-2 F(x, u) \geqslant \frac{a_{0}}{|u|^{2}} F(x, u)
$$

for all $u \in \mathbb{R}$, with $|u| \geqslant \mathrm{L}_{1}$ and a.e. $x \in[0, l]$.

$\left(\mathrm{F}_{4}\right)$ For some $r_{0}>0$

$$
\mathrm{F}(\mathrm{x}, \mathrm{u}) \geqslant 0, \quad \forall|\mathrm{u}| \leqslant \mathrm{r}_{0}, \quad \forall x \in[0, \mathrm{l}] \quad \text { or } \quad \mathrm{F}(\mathrm{x}, \mathrm{u}) \leqslant 0, \quad \forall|\mathrm{u}| \leqslant \mathrm{r}_{0}, \quad \forall x \in[0, \mathrm{l}] .
$$

$\left(F_{5}\right) F(x,-u)=F(x, u)$ for all $u \in \mathbb{R}$, and a.e. $x \in[0, l]$.

Theorem 1.1. Suppose that $\mathrm{F}(\mathrm{x}, \mathrm{u})$ satisfies $\left(\mathrm{F}_{1}\right)-\left(\mathrm{F}_{4}\right)$, if 0 is an eigenvalue of $-\frac{\mathrm{d}^{2}}{\mathrm{~d} x^{2}}+\mathrm{p}(\mathrm{x})$, then problem (1.1) has at least one nontrivial solution.

Remark 1.2. $\left(\mathrm{F}_{3}\right)$ is weaker than $\left(\mathrm{F}_{0}^{\prime}\right)$. It is easy to show that $\mathrm{F}(\mathrm{x}, \mathrm{u})=|\mathrm{u}|^{2} \ln \left(1+|\mathrm{u}|^{2}\right)+\sin |\mathrm{u}|^{2}-\ln \left(1+|\mathrm{u}|^{2}\right)$ for all $u \in \mathbb{R}$ and a.e. $x \in[0, l]$, satisfies our assumption $\left(\mathrm{F}_{3}\right)$ but not the condition $\left(\mathrm{F}_{0}^{\prime}\right)$ in $\mathbb{R}$.

Theorem 1.3. Suppose that $\mathrm{F}(\mathrm{x}, \mathrm{u})$ satisfies $\left(\mathrm{F}_{2}\right),\left(\mathrm{F}_{3}\right)$, and $\left(\mathrm{F}_{5}\right)$, then problem (1.1) has infinitely many solutions.

\subsubsection{The subquadratic case}

For the subquadratic case, we make the following assumptions

$\left(\mathrm{SF}_{1}\right)$ There exists $r>0$ such that $F(x,-u)=F(x, u)$ for all $|u| \leqslant r$ and $x \in[0, l]$.

$\left(\mathrm{SF}_{2}\right) \mathrm{F}(\mathrm{x}, 0)=0$ for $x \in[0, \mathrm{l}]$, and $\lim _{|\mathfrak{u}| \rightarrow 0} \frac{\mathrm{F}(\mathrm{x}, \mathrm{u})}{|\mathrm{u}|^{2}}=+\infty$ uniformly for $x \in[0, \mathrm{l}]$.

Theorem 1.4. Suppose that $\mathrm{F}(\mathrm{x}, \mathrm{u})$ satisfies $\left(\mathrm{SF}_{1}\right)$ and $\left(\mathrm{SF}_{2}\right)$, then problem (1.1) possesses infinitely many solutions.

Remark 1.5. Under $\left(\mathrm{SF}_{1}\right)$ and $\left(\mathrm{SF}_{2}\right)$, by the well-known theorem (in [3]), we can also get a sequence of critical value $c_{k}$ of $\Phi(u)$ (defined in next section) with $c_{k} \leqslant c_{k+1}<0$ for $k \in \mathbb{N}$, and $\left\{c_{k}\right\}$ converges to zero.

\subsubsection{The asymptotically quadratic case}

For the asymptotically quadratic case, we assume

$\left(\mathrm{AF}_{1}\right) \mathrm{F}(\mathrm{x}, \mathrm{u}) \geqslant 0$ for all $(x, u) \in[0, l] \times \mathbb{R}$, and there exist constants $\mu \in(0,2)$ and $R_{1}>0$ such that $\langle f(x, u), u\rangle \leqslant \mu F(x, u)$ for all $x \in[0, l]$ and $|u| \geqslant R_{1} ;$

$\left(\mathrm{AF}_{2}\right) \lim _{|\mathfrak{u}| \rightarrow 0} \frac{\mathrm{F}(\mathrm{x}, \mathfrak{u})}{|\mathfrak{u}|^{2}}=\infty$ uniformly for $x \in[0, l]$, and there exist constants $c_{2}, R_{2}$ such that $F(x, u) \leqslant c_{2}|u|$ for all $x \in[0, l]$ and $|u| \leqslant R_{2}$;

$\left(\mathrm{AF}_{3}\right) \liminf _{|\mathfrak{u}| \rightarrow \infty} \frac{\mathrm{F}(\mathrm{x}, \mathrm{u})}{|\mathfrak{u}|} \geqslant \mathrm{d}>0$ uniformly for $x \in[0, \mathrm{l}]$.

Theorem 1.6. Assume that $\left(\mathrm{AF}_{1}\right)-\left(\mathrm{AF}_{3}\right)$ hold, $\mathrm{F}(\mathrm{x},-\mathrm{u})=\mathrm{F}(\mathrm{x}, \mathrm{u})$, then (1.1) possesses infinitely many solutions.

\subsection{Subharmonic solutions of elliptic equation}

We assume the following hypotheses.

$\left(\mathrm{HF}_{1}\right) \lim _{|\mathrm{u}| \rightarrow 0} \frac{\mathrm{F}(\mathrm{x}, \mathrm{u})}{|\mathfrak{u}|^{2}}=0$ uniformly for a.e. $x \in[0, \mathrm{l}]$.

$\left(\mathrm{HF}_{2}\right)$ There exist constants $\mathrm{a}_{0}>0$, and $\mathrm{L}_{1}>0$, such that

$$
\langle f(x, u), u\rangle-2 F(x, u) \geqslant \frac{a_{0}}{|u|^{2}} F(x, u)
$$

for all $u \in \mathbb{R}$, with $|u| \geqslant \mathrm{L}_{1}$ and a.e. $x \in[0, l]$.

$\left(\mathrm{HF}_{3}\right) \mathrm{F}(\mathrm{x}, \mathrm{u}) \geqslant 0,(\mathrm{x}, \mathrm{u}) \in[0, \mathrm{l}] \times \mathbb{R}$. 
Theorem 1.7. Suppose that $\mathrm{p}(\mathrm{x})=\mathrm{m}^{2} \omega^{2}$, where $\mathrm{m}$ is a nonnegative integer, $\omega=\frac{2 \pi}{l}$, and $\mathrm{F}$ satisfies (A), $\left(\mathrm{HF}_{1}\right)-\left(\mathrm{HF}_{3}\right)$, and the following condition

$$
\left(\mathrm{HF}_{4}\right) \liminf _{|\mathfrak{u}| \rightarrow \infty} \frac{\mathrm{F}(\mathrm{x}, \mathrm{u})}{|\mathfrak{u}|^{2}}>\frac{1+2 \mathrm{~m}}{2} \omega^{2} \text { uniformly for a.e. } x \in[0, \mathrm{l}] \text {. }
$$

Then there exist a sequence $\left\{\mathrm{k}_{\mathbf{j}}\right\} \in \mathbb{N}, \mathrm{k}_{\mathbf{j}} \rightarrow \infty$, and corresponding distinct $\mathrm{k}_{\mathbf{j}}$ l periodic solutions of problem (1.1).

Remark 1.8. In [22], Ye and Tang studied the existence of infinitely many solutions for problem (1.2) under the condition $\left(\mathrm{F}_{0}^{\prime}\right)$. As stated in Remark 1.2, $\left(\mathrm{HF}_{2}\right)$ is weaker than $\left(\mathrm{F}_{0}^{\prime}\right)$. Hence, our result generalizes and improves Theorem 2 in [22].

\section{Variational setting and proofs of the main results}

In order to apply the variational methods, we first recall some related preliminaries and establish corresponding variational framework for our problem (1.1), and then give the proofs of all the main results.

\subsection{Periodic solutions of elliptic equation}

Let

$$
H_{l}^{1}=\left\{u:[0, l] \rightarrow \mathbb{R} \mid u \text { is absolutely continuous, } u(0)=u(l), \text { and } u^{\prime} \in L^{2}(0, l ; \mathbb{R})\right\}
$$

be a Hilbert space endowed with the norm

$$
\|u\|=\left(\int_{0}^{l}|u(x)|^{2} d x+\int_{0}^{l}\left|u^{\prime}(x)\right|^{2} d x\right)^{\frac{1}{2}}
$$

for $u \in H_{l}^{1}$. According to the Sobolev embedding theorem, $H_{l}^{1}$ is compactly embedded into $L^{p}([0, l], \mathbb{R})$ for $1 \leqslant p \leqslant \infty$ and there exists $\tau_{p}>0$ such that

$$
\|\mathrm{u}\|_{\mathrm{p}} \leqslant \tau_{\mathrm{p}}\|\mathrm{u}\|, \quad \forall \mathrm{u} \in \mathrm{H}_{\mathrm{l}}^{1},
$$

where $\|\cdot\|_{p}$ denotes the usual norm on $\mathrm{L}^{p}$ for all $1 \leqslant p \leqslant \infty$.

It follows from assumption (A) that the functional $\Phi$ on $\mathrm{H}_{l}^{1}$ given by

$$
\Phi(u)=\frac{1}{2} \int_{0}^{l}\left|u^{\prime}(x)\right|^{2} d x-\frac{1}{2} \int_{0}^{l} p(x) u^{2}(x) d x-\int_{0}^{l} F(x, u) d x
$$

is continuously differentiable on $\mathrm{H}_{\mathrm{l}}^{1}$. Moreover, one has

$$
\left\langle\Phi^{\prime}(u), v\right\rangle=\int_{0}^{l}\left[u^{\prime}(x) v^{\prime}(x)-p(x) u(x) v(x)-f(x, u) v(x)\right] d x
$$

for all $u, v \in H_{l}^{1}$. It is well-known that the solutions of problem (1.1) correspond to the critical points of $\Phi$ (see $[5,12,16,27])$.

Let

$$
\mathrm{Q}(\mathrm{x})=\frac{1}{2}\|\mathrm{u}\|^{2}-\frac{1}{2} \int_{0}^{\mathrm{l}}(\mathrm{p}(\mathrm{x})+1) \mathrm{u}^{2}(\mathrm{x}) \mathrm{d} x=\frac{1}{2}((\mathrm{I}-\mathrm{K}) \mathrm{u}, \mathrm{u}),
$$

where $\mathrm{K}: \mathrm{H}_{\mathrm{l}}^{1} \rightarrow \mathrm{H}_{\mathrm{l}}^{1}$ is the linear self-adjoint operator. Clearly, $\mathrm{K}$ is compact. Hence, we can decompose $\mathrm{H}_{l}^{1}$ into the orthogonal sum of invariant subspaces under $(I-K)$ due to classical spectral theory

$$
\mathrm{H}_{\mathrm{l}}^{1}=\mathrm{H}^{-} \oplus \mathrm{H}^{0} \oplus \mathrm{H}^{+} .
$$

Here $\mathrm{H}^{0}=\mathrm{N}(\mathrm{I}-\mathrm{K}), \mathrm{H}^{-}$and $\mathrm{H}^{+}$are such that, for some $\delta>0$,

$$
\begin{aligned}
& \mathrm{Q}(\mathrm{u}) \leqslant-\frac{\delta}{2}\|\mathrm{u}\|^{2}, \quad \text { if } \mathrm{u} \in \mathrm{H}^{-}, \\
& \mathrm{Q}(\mathrm{u}) \geqslant \frac{\delta}{2}\|\mathrm{u}\|^{2}, \quad \text { if } \mathrm{u} \in \mathrm{H}^{+} .
\end{aligned}
$$




\subsubsection{The superquadratic case}

Let $\left\{e_{j}\right\}_{j \in N}$ be a basis for $H_{l}^{1}$ and define $X_{j}, Y_{k}$, and $Z_{k}$ as in $[4,5,10,16,27]$.

Definition 2.1 ([19]). A sequence $\left\{\alpha_{n}\right\} \in \mathbb{N}^{2}$ is admissible if, for every $\alpha \in \mathbb{N}^{2}$, there is $m \in \mathbb{N}$ such that $\alpha_{n} \geqslant \alpha$ for all $n \geqslant m$.

Lemma $2.2([5,15-17])$. If $Z_{k}=\overline{\bigoplus_{j} X_{j}}$, then $\beta_{k}=\sup _{u \in Z_{k}\|u\|=1}\|u\|_{\infty} \rightarrow 0$ as $k \rightarrow \infty$.

Lemma 2.3. Suppose $(\mathrm{A})$ and $\left(\mathrm{F}_{2}\right)-\left(\mathrm{F}_{3}\right)$ hold, then $\Phi$ satisfies the $(\mathrm{C})^{*}$ condition.

Proof. Let $\mathrm{X}=\mathrm{H}_{1}^{1}, \mathrm{X}^{1}=\mathrm{H}^{+}$with $\left\{\boldsymbol{e}_{\mathfrak{n}}\right\}_{\mathfrak{n} \geqslant 1}$ being its Hilbertian basis, $\mathrm{X}^{2}=\mathrm{H}^{-} \oplus \mathrm{H}^{0}$ and define

$$
X_{n}^{1}=\operatorname{span}\left\{e_{1}, e_{2}, \ldots, e_{n}\right\}, \quad n \in \mathbb{N}, \quad X_{n}^{2}=X^{2}, \quad n \in \mathbb{N}, \quad X^{j}=\overline{\bigcup_{n \in \mathbb{N}} X_{n}^{j}}, j=1,2 .
$$

Let $\left\{u_{\alpha_{n}}\right\}$ be a sequence in $H_{l}^{1}$ such that $\left\{\alpha_{n}\right\}$ is admissible and satisfying

$$
u_{\alpha_{n}} \in X_{\alpha_{n}}, \sup \Phi\left(u_{\alpha_{n}}\right)<\infty,\left(1+\left\|u_{\alpha_{n}}\right\|\right)\left\|\Phi^{\prime}\left(u_{\alpha_{n}}\right)\right\| \rightarrow 0 .
$$

Hence, there exists a constant $M>0$ such that

$$
\left|\Phi\left(u_{\alpha_{n}}\right)\right| \leqslant M, \quad\left(1+\left\|u_{\alpha_{n}}\right\|\right)\left\|\Phi^{\prime}\left(u_{\alpha_{n}}\right)\right\| \leqslant M
$$

for all $n$.

Now we prove the sequence $\left\{u_{\alpha_{n}}\right\}$ is bounded. If $\left\{u_{\alpha_{n}}\right\}$ is unbounded, we can assume that $\left\|u_{\alpha_{n}}\right\| \rightarrow \infty$ as $\mathrm{n} \rightarrow \infty$. Let $w_{\alpha_{n}}=\frac{\mathfrak{u}_{\alpha_{n}}}{\left\|\mathfrak{u}_{\alpha_{n}}\right\|}$, then $\left\|w_{\alpha_{n}}\right\|=1$. Passing, if necessary, to a subsequence, for some $w \in \mathrm{H}_{l}^{1}$ we obtain

$$
w_{\alpha_{n}} \rightarrow w \text { weakly in } \mathrm{H}_{l}^{1}, \quad w_{\alpha_{n}} \rightarrow w \text { in } \mathrm{C}([0, l] ; \mathbb{R})
$$

as $n \rightarrow \infty$. Since $p(x)$ is continuous and l-periodic in $x$, we can find a positive constant $p_{0}$ such that

$$
|p(x)| \leqslant p_{0}, \quad \forall x \in[0, l] .
$$

Using (2.5), (2.6), and (2.7), we have

$$
\left|\int_{0}^{l} \frac{\mathrm{F}\left(x, \mathrm{u}_{\alpha_{n}}\right)}{\left\|\mathrm{u}_{\alpha_{n}}\right\|^{2}} \mathrm{~d} x-\frac{1}{2}\right| \leqslant \frac{\left|\Phi\left(\mathrm{u}_{\alpha_{n}}\right)\right|}{\left\|\mathrm{u}_{\alpha_{n}}\right\|^{2}}+\frac{1}{2}\left|\int_{0}^{l}(\mathrm{p}(\mathrm{x})+1) w_{\alpha_{n}}^{2}(x) \mathrm{d} x\right| \leqslant \frac{M}{\left\|u_{\alpha_{n}}\right\|^{2}}+\frac{1}{2}\left(p_{0}+1\right) l\left\|w_{\alpha_{n}}\right\|_{\infty}^{2} .
$$

From $\left(F_{2}\right)$, we see that there exists a positive constant $r_{1}>L_{1}$ such that $F(x, u) \geqslant 0$ for all $u \in \mathbb{R}$ with $|u| \geqslant r_{1}$ and a.e. $x \in[0, l]$. Noting that, the assumption (A) implies that

$$
|F(x, u)| \leqslant a_{1} b(x), \quad|f(x, u)| \leqslant a_{1} b(x)
$$

for all $u \in \mathbb{R}$ with $|u| \leqslant r_{1}$ and a.e. $x \in[0, l]$, here $a_{1}=\max _{0 \leqslant s \leqslant r_{1}} a(s)$. Then we obtain

$$
F(x, u) \geqslant-a_{1} b(x)
$$

for all $u \in \mathbb{R}$ and a.e. $x \in[0, l]$.

If $w \equiv 0$, on one hand, by (2.8), we have

$$
\lim _{n \rightarrow \infty} \int_{0}^{l} \frac{F\left(x, u_{\alpha_{n}}\right)}{\left\|u_{\alpha_{n}}\right\|} d x=\frac{1}{2}
$$


On the other hand, we deduce from $\left(\mathrm{F}_{3}\right),(2.5)$ and (2.9) that

$$
\begin{aligned}
\int_{\left\{x|| u_{\alpha_{n}} \mid \geqslant r_{1}\right\}} & \frac{\left|F\left(x, u_{\alpha_{n}}\right)\right|}{\left|u_{\alpha_{n}}\right|^{2}} d x \\
& \leqslant a_{0}^{-1} \int_{0}^{l}\left(\left\langle f\left(x, u_{\alpha_{n}}\right), u_{\alpha_{n}}\right\rangle-2 F\left(x, u_{\alpha_{n}}\right)\right) d x-a_{0}^{-1} \int_{\left\{x \| u_{\alpha_{n}} \mid<r_{1}\right\}}\left(\left\langle f\left(x, u_{\alpha_{n}}\right), u_{\alpha_{n}}\right\rangle-2 F\left(x, u_{\alpha_{n}}\right)\right) d x \\
& \leqslant a_{0}^{-1}\left(2 \Phi\left(u_{\alpha_{n}}\right)-\left\langle\Phi^{\prime}\left(u_{\alpha_{n}}\right), u_{\alpha_{n}}\right\rangle\right)+a_{0}^{-1}\left(r_{1}+2\right) \int_{\left\{x \| u_{\alpha_{n}} \mid<r_{1}\right\}} a_{1} b(x) d x \\
& \leqslant 3 a_{0}^{-1} M+a_{0}^{-1}\left(r_{1}+2\right) a_{1}\|b\|_{1} .
\end{aligned}
$$

Then, we obtain

$$
\begin{aligned}
\left|\int_{0}^{l} \frac{F\left(x, u_{\alpha_{n}}\right)}{\left\|u_{\alpha_{n}}\right\|^{2}} d x\right| & \leqslant \int_{\left\{x \| u_{\alpha_{n}} \mid \geqslant r_{1}\right\}} \frac{\left|F\left(x, u_{\alpha_{n}}\right)\right|}{\left\|u_{\alpha_{n}}\right\|^{2}} d x+\int_{\left\{x \| u_{\alpha_{n}} \mid<r_{1}\right\}} \frac{\left|F\left(x, u_{\alpha_{n}}\right)\right|}{\left\|u_{\alpha_{n}}\right\|^{2}} d x \\
& \leqslant \int_{\left\{x \| u_{\alpha_{n}} \mid \geqslant r_{1}\right\}} \frac{\left|\mathrm{F}\left(x, u_{\alpha_{n}}\right)\right|}{\left|u_{\alpha_{n}}\right|^{2}}\left|w_{\alpha_{n}}\right|^{2} \mathrm{~d} x+\frac{a_{1}\|b\|_{1}}{\left\|u_{\alpha_{n}}\right\|^{2}} \\
& \leqslant\left\|w_{\alpha_{n}}\right\|_{\infty}^{2}\left(3 a_{0}^{-1} M+a_{0}^{-1}\left(r_{1}+2\right) a_{1}\|b\|_{1}\right)+\frac{a_{1}\|b\|_{1}}{\left\|u_{\alpha_{n}}\right\|^{2}} \rightarrow 0
\end{aligned}
$$

as $n \rightarrow \infty$, which contradicts to (2.11). So $w \neq \equiv 0$. Let $L=\{x \in[0, l],|w(x)|>0\}$, then $|L|>0$, and $\left|u_{n}\right| \rightarrow+\infty$ as $n \rightarrow+\infty$ for a.e. $x \in$ L.

From $\left(\mathrm{F}_{2}\right)$, one has

$$
\lim _{n \rightarrow+\infty} \frac{F\left(x, u_{\alpha_{n}}\right)}{\left|u_{\alpha_{n}}\right|^{2}}=+\infty \text { a.e. on L. }
$$

We conclude from (2.10) and Fatou Lemma that

$$
\begin{aligned}
\liminf _{n \rightarrow+\infty} \int_{0}^{l} \frac{F\left(x, u_{\alpha_{n}}\right)}{\left\|u_{\alpha_{n}}\right\|^{2}} d x & \geqslant \liminf _{n \rightarrow+\infty}\left(\int_{L} \frac{\left|F\left(x, u_{\alpha_{n}}\right)\right|}{\left|u_{\alpha_{n}}\right|^{2}}\left|w_{\alpha_{n}}\right|^{2} d x-\frac{a_{1}}{\left\|u_{\alpha_{n}}\right\|^{2}} \int_{[0, l] \backslash L} b(x) d x\right) \\
& \geqslant \liminf _{n \rightarrow+\infty}\left(\int_{L} \frac{\left|F\left(x, u_{\alpha_{n}}\right)\right|}{\left|u_{\alpha_{n}}\right|^{2}}\left|w_{\alpha_{n}}\right|^{2} d x-\frac{a_{1}\|b\|_{1}}{\left\|u_{\alpha_{n}}\right\|^{2}}\right)=+\infty,
\end{aligned}
$$

which is contradiction to (2.8), so $\left\|\mathfrak{u}_{\alpha_{n}}\right\|$ is bounded. By similar arguments as those in Proposition 4.1 in [12], we get that the $(\mathrm{C})^{*}$ condition is satisfied. The proof is completed.

Lemma $2.4([5,11])$. If the Cerami sequence of $\Phi$ is bounded, then its subsequence converges weakly to solution of problem (1.1).

\section{Proof of Theorem 1.1.}

Step 1. We claim that $\Phi$ has a local linking at 0 with respect to $\left(X^{1}, X^{2}\right)$. Here we only consider the case where 0 is an eigenvalue of $-\frac{d^{2}}{d x^{2}}-p(x)$ and $F(x, u) \geqslant 0$ for all $|u| \leqslant r, x \in[0, l]$. The other cases are similar.

Using $\left(F_{1}\right)$, we can get that there exists $l_{1}>0$ such that

$$
|\mathrm{F}(\mathrm{x}, \mathrm{u})| \leqslant \frac{\delta}{2}|\mathrm{u}|^{2}
$$

for all $|u| \leqslant l_{1}$ and a.e. $x \in[0, l]$. Due to (2.12), (2.1), and (2.4), for $u \in X^{1}=H^{+}$with $\|u\| \leqslant r_{3} \triangleq \frac{l_{1}}{\tau_{\infty}}$, we have

$$
\Phi(u) \geqslant \frac{\delta}{2}\|u\|^{2}-\frac{\delta}{2} \int_{0}^{l}|u|^{2} d x \geqslant 0
$$


which implies that

$$
\Phi(u) \geqslant 0, \quad \forall u \in X^{1} \text { with }\|u\| \leqslant r_{3} .
$$

Set $u=u^{-}+u^{0} \in X^{2}=H^{-} \bigoplus H^{0}$ satisfying $\|u\| \leqslant r_{4} \triangleq \frac{r_{0}}{\tau_{\infty}}$, by (2.1), (2.3), and ( $\left.F_{4}\right)$ we get

$$
\Phi(u) \leqslant-\frac{\delta}{2}\left\|u^{-}\right\|^{2},
$$

which implies that

$$
\Phi(\mathrm{u}) \leqslant 0, \quad \forall \mathrm{u} \in \mathrm{X}^{2} \text { with }\|\mathrm{u}\| \leqslant \mathrm{r}_{4} .
$$

Let $r=\min \left\{r_{3}, r_{4}\right\}$, then $\Phi$ has a local linking at 0 .

Step 2. We claim that $\Phi$ maps bounded sets into bounded sets.

Assume that $\|u\| \leqslant M$ for some positive constant $M$. Combining (2.1) and (2.7) with (A), we have

$$
|\Phi(u)| \leqslant \frac{1}{2} \int_{0}^{l}\left|u^{\prime}\right|^{2} d x+\frac{p_{0}}{2} \int_{0}^{l} u^{2} d x+a_{M} \int_{0}^{l} b(x) d x \leqslant \frac{1+p_{0}}{2} M^{2}+a_{M}\|b\|_{1}
$$

for all $u \in H_{l}^{1}$, where $a_{M}=\max _{0 \leqslant s \leqslant \tau_{\infty} M} a(s)$.

Step 3. We claim that for every $m \in \mathbb{N}$,

$$
\Phi(\mathrm{u}) \rightarrow-\infty \text { as }\|\mathrm{u}\| \rightarrow \infty, \text { on } X_{\mathrm{m}}^{1} \oplus \mathrm{X}^{2} .
$$

Evidently, there exists $d_{1}>0$ such that

$$
\|u\| \leqslant d_{1}\|u\|_{2}, \quad \forall u \in X_{m}^{1} \oplus X^{2} .
$$

By $\left(F_{2}\right)$, there exists a constant $l_{2}>0$ such that $F(x, u) \geqslant \frac{1}{2} d_{1}^{2}\left(p_{0}+2\right)|u|^{2}$ for all $|u| \geqslant l_{2}$ and a.e. $x \in[0, l]$. Applying (A), we have $|F(x, u)| \leqslant \max _{s \in\left[0, l_{2}\right]} a(s) b(x)$ for all $|u| \leqslant l_{2}$ and a.e. $x \in[0, l]$, which implies that

$$
F(x, u) \geqslant \frac{1}{2} d_{1}^{2}\left(p_{0}+2\right)|u|^{2}-M_{1}-\max _{s \in\left[0, l_{2}\right]} a(s) b(x)
$$

for all $u \in \mathbb{R}$, and a.e. $x \in[0, l]$, where $M_{1}=\frac{1}{2} d_{1}^{2}\left(p_{0}+2\right) l_{2}^{2}$, and $p_{0}$ is the same as in (2.7). Combining this with (2.13), we get, for $u \in X_{m}^{1} \oplus X^{2}$,

$$
\Phi(u) \leqslant \frac{p_{0}+1}{2}\|u\|^{2}-\int_{0}^{l} F(x, u) d x \leqslant-\frac{1}{2}\|u\|^{2}+M_{1} l+M_{2}
$$

which implies that

$$
\Phi(\mathrm{u}) \rightarrow-\infty \text { as }\|\mathrm{u}\| \rightarrow \infty \text { on } \mathrm{X}_{\mathrm{m}}^{1} \oplus \mathrm{X}^{2},
$$

where $M_{2}=\max _{s \in\left[0, l_{2}\right]} a(s)\|b\|_{L^{1}}$. Therefore, by the local lining theorem (see $\left.[6,17,27]\right)$, the proof is complete.

Proof of Theorem 1.3. Obviously, we can prove that $\Phi$ satisfies condition (C) in the similar way as Lemma 2.3, and $\Phi(-\mathfrak{u})=\Phi(\mathfrak{u})$ by using $\left(F_{5}\right)$. Then, we only need to check conditions $\left(A_{1}\right)$ and $\left(A_{2}\right)$ of the fountain theorem (see $[4,6,7,14,15,25])$.

Step 1. In fact, for each $u \in Y_{k}$, there exists a constant $d_{2}>0$ such that

$$
\|u\| \leqslant d_{2}\|u\|_{2} .
$$

Applying condition $\left(F_{2}\right)$, there is $l_{3}>0$ such that $F(x, u) \geqslant\left(1+p_{0}\right) d_{2}^{2}|u|^{2}$ for all $|u| \geqslant l_{3}$ and a.e. $x \in[0, l]$. 
From assumption (A), one has $|F(x, u)| \leqslant a_{2} b(x)$ for all $u \in \mathbb{R}$ with $|u| \leqslant l_{3}$ and a.e. $x \in[0, l]$, where $\mathrm{a}_{2}=\max _{0 \leqslant s \leqslant l_{3}} \mathrm{a}(s)$. Then,

$$
F(x, u) \geqslant\left(1+p_{0}\right) d_{2}^{2}\left(|u|^{2}-l_{3}^{2}\right)-a_{2} b(x)
$$

for all $u \in \mathbb{R}$ and a.e. $x \in[0, l]$.

Therefore, for all $u \in Y_{k}$, combining (2.14) with (2.15), we have

$$
\begin{aligned}
\Phi(\mathfrak{u}) & \leqslant \frac{1}{2}\left\|u^{\prime}\right\|_{2}^{2}+\frac{p_{0}}{2}\|u\|_{2}^{2}-\left(1+p_{0}\right) d_{2}^{2}\left(\|u\|_{2}^{2}-l_{3}^{2} l\right)+a_{2}\|b\|_{1} \\
& \leqslant-\frac{1+p_{0}}{2}\|u\|^{2}+\left(1+p_{0}\right) d_{2}^{2} l_{3}^{2} l+a_{2}\|b\|_{1},
\end{aligned}
$$

which implies that $\Phi(u) \rightarrow-\infty$ as $\|u\| \rightarrow \infty$ in $Y_{k}$. Hence, $\left(A_{1}\right)$ holds.

Step 2. Let us define $r_{k}=\beta_{k}^{-1}$. Applying lemma 2.2, we have

$$
\mathrm{r}_{\mathrm{k}} \rightarrow+\infty \text {, as } \mathrm{k} \rightarrow \infty
$$

Then by (2.4), we get that $Z_{k} \subset H^{+}$and $r_{k}^{2} \geqslant 4 \delta^{-1} a_{3}\|b\|_{1}$ for $k$ large enough. Thus, for all $u \in Z_{k}$ with $\|u\|=r_{k}$, we have $\|u\|_{\infty} \leqslant 1$. Hence,

$$
\Phi(u) \geqslant \frac{\delta}{2}\|u\|^{2}-a_{3}\|b\|_{1} \geqslant \frac{\delta}{4} r_{k}^{2} .
$$

where $a_{3}=\max _{0 \leqslant s \leqslant 1} a(s)$. Therefore, it follows from (2.16) and the above expression that

$$
\inf _{\mathfrak{u} \in \mathbf{Z}_{k},\|u\|=r_{k}} \Phi(\mathfrak{u}) \rightarrow+\infty \text { as } k \rightarrow \infty
$$

Hence, $\left(A_{2}\right)$ is proved.

\subsubsection{The subquadratic case}

Proof of Theorem 1.4. We consider the truncated functional

$$
I(u)=\frac{1}{2}\|u\|^{2}+\left(-\frac{1}{2} \int_{0}^{l}(p(x)+1) d x-\int_{0}^{l} F(x, u) d x\right) h(\|u\|)
$$

for all $u \in H_{l}^{1}$, where $h: \mathbb{R}^{+} \rightarrow[0, l]$ is a non-increasing $C^{1}$ function such that $h(s)=1$ for $0 \leqslant s \leqslant \frac{\delta}{2 \tau_{\infty}}$, and $h(s)=0$ for $s \geqslant \frac{\delta}{\tau_{\infty}}$. Clearly, $\mathrm{I} \in \mathrm{C}^{1}\left(\mathrm{H}_{\mathrm{l}}^{1}, \mathbb{R}\right)$ and $\mathrm{I}(0)=0$.

Case 1 . $\|u\| \geqslant \frac{\delta}{\tau_{\infty}}$. It is easy to see $I(u)=\|u\|^{2}$, which shows that

$$
\mathrm{I}(\mathrm{u}) \rightarrow+\infty \text { as }\|\mathrm{u}\| \rightarrow \infty \text {. }
$$

Hence, I is bounded from below and the (PS) condition holds. By lemma 2.4 we know that this is enough to get a solution of problem (1.1).

Case 2. $\|u\| \leqslant \frac{\delta}{2 \tau_{\infty}}$. By the sobolev embedding, one has

$$
|\mathfrak{u}(x)| \leqslant\|\mathfrak{u}(x)\|_{\infty} \leqslant \tau_{\infty}\|\mathfrak{u}(x)\| \leqslant \frac{\delta}{2}, \forall x \in[0, l] .
$$

Applying $\left(\mathrm{SF}_{1}\right)$, we have $\mathrm{F}(\mathrm{x},-\mathrm{u})=\mathrm{F}(\mathrm{x}, \mathrm{u}), \mathrm{x} \in[0, \mathrm{l}]$, and $\mathrm{I}(\mathrm{u})=\mathrm{I}(-\mathrm{u})$.

For any $k \in \mathbb{N}$, set $E_{k}=\bigoplus_{j=1}^{k} X_{j}$, where $X_{j}=\operatorname{span}\left\{e_{j}\right\}$, there is a constant $d_{k}>0$ such that

$$
\mathrm{d}_{\mathrm{k}}\|\mathrm{u}\|_{2} \geqslant\|\mathrm{u}\|, \quad \forall \mathrm{u} \in \mathrm{E}_{\mathrm{k}}
$$


By $\left(\mathrm{SF}_{2}\right)$, there exists $r_{5}>0$ such that

$$
F(x, u) \geqslant\left(p_{0}+2\right) d_{k}^{2}|u|^{2}
$$

for all $|u| \leqslant r_{5}$ and $x \in[0, l]$. Hence, for $u \in E_{k}$ with $\|u\|=l_{k}=\frac{1}{2} \min \left\{1, \frac{r_{5}}{d_{k}}\right\}$, applying (2.7), (2.17) and (2.18), we have

$$
\mathrm{I}(\mathrm{u}) \leqslant \frac{1}{2}\|\mathrm{u}\|^{2}+\frac{p_{0}+1}{2}\|\mathrm{u}\|_{2}^{2}-\int_{0}^{l} \mathrm{~F}(\mathrm{x}, \mathrm{u}) \mathrm{d} x \leqslant \frac{p_{0}+2}{2}\|\mathrm{u}\|^{2}-\left(\mathrm{p}_{0}+2\right)\|\mathrm{u}\|^{2}=-\frac{\mathrm{p}_{0}+2}{2} l_{\mathrm{k}^{\prime}}^{2}
$$

which implies that

$$
\left\{u \in E_{k}:\|u\|=l_{k}\right\} \subset\left\{u \in H_{l}^{1}: I(u) \leqslant-\frac{p_{0}+2}{2} l_{k}^{2}\right\} .
$$

Let $A_{k}=\left\{u \in H_{l}^{1}: I(u) \leqslant-\frac{p_{0}+2}{2} l_{k}^{2}\right\}$, by the properties of genus we get that

$$
\gamma\left(A_{k}\right) \geqslant \gamma\left(\left\{u \in E_{k}:\|u\|=l_{k}\right\}\right) \geqslant k,
$$

which implies that $A_{k} \in \Gamma_{k}$ and

$$
\sup _{\mathfrak{u} \in A_{k}} I(u) \leqslant-\frac{\left(p_{0}+2\right) l_{k}^{2}}{2}<0 .
$$

By virtue of Theorem 1 (see [3] and its reference), we can see that I admits a sequence of critical points $\left\{\mathfrak{u}_{k}\right\}$ such that $\mathrm{I}\left(\mathfrak{u}_{\mathrm{k}}\right) \leqslant 0, \mathfrak{u}_{\mathrm{k}} \neq 0$ and $\mathfrak{u}_{\mathrm{k}} \rightarrow 0$ as $\mathrm{k} \rightarrow \infty$, when $\left\|\mathfrak{u}_{\mathrm{k}}\right\| \leqslant \frac{\delta}{2 \tau_{\infty}}$. In fact, $\mathrm{I}(\mathfrak{u})=\Phi(\mathfrak{u})$ with $\|u\| \leqslant \frac{\delta}{2 \tau_{\infty}}$. Hence, the sequence of critical points $\left\{\mathfrak{u}_{k}\right\}$ satisfies $\Phi\left(u_{k}\right) \leqslant 0, u_{k} \neq 0$ and $u_{k} \rightarrow 0$ as $k \rightarrow \infty$ with $\left\|u_{k}\right\| \leqslant \frac{\delta}{2 \tau_{\infty}}$.

By the two cases we have discussed above, the proof of Theorem 1.4 is finished.

\subsubsection{The asymptotically quadratic case}

In this subsection, the space and space decomposition we talked about are same as those established before. To get our next result, we should use the following inner product and norm

$$
(u, v)=\left(|\mathcal{A}|^{\frac{1}{2}} u,|\mathcal{A}|^{\frac{1}{2}} v\right)_{2}+\left(u^{0}, v^{0}\right)_{2},\|u\|=(u, u)^{\frac{1}{2}},
$$

where $u=u^{-}+u^{0}+u^{+}$and $v=v^{-}+v^{0}+v^{+}$with respect to the decomposition (2.2), the operator

$$
\mathcal{A}=-\frac{\mathrm{d}^{2}}{\mathrm{dt}^{2}}-\mathrm{p}(\mathrm{x})
$$

So the functional $\Phi$ defined on $\mathrm{H}_{l}^{1}$ is

$$
\Phi(\mathfrak{u})=\frac{1}{2} \int_{0}^{\mathfrak{l}}\left(\left|\mathrm{u}^{\prime}\right|^{2}-\langle p(x) \mathfrak{u}, \mathfrak{u}\rangle\right) \mathrm{d} x-\Psi(\mathfrak{u})=\frac{1}{2}\left\|\mathrm{u}^{+}\right\|^{2}-\frac{1}{2}\left\|\mathrm{u}^{-}\right\|^{2}-\Psi(\mathfrak{u})
$$

for all $u=u^{-}+u^{0}+u^{+} \in H_{l}^{1}=H^{-} \bigoplus H^{0} \bigoplus H^{+}$, where $\Psi(u)=\int_{0}^{l} F(x, u) d x$.

Note that $\left(\mathrm{AF}_{1}\right)$ and $\left(\mathrm{AF}_{3}\right)$ imply

$$
\mathrm{F}(\mathrm{x}, \mathrm{u}) \leqslant \mathrm{C}_{1}\left(1+|\mathrm{u}|^{\mu}\right), \quad \forall(x, \mathrm{u}) \in[0, \mathrm{l}] \times \mathbb{R}
$$

for some $\mathrm{C}_{1}>0$.

Proposition 2.5 ([24]). Suppose that $\left(\mathrm{AF}_{1}\right)$ and $\left(\mathrm{AF}_{3}\right)$ are satisfied. Then $\Psi \in \mathrm{C}^{1}\left(\mathrm{H}_{\mathrm{l}}^{1}, \mathbb{R}\right)$ and $\Psi^{\prime}: \mathrm{H}_{\mathrm{l}}^{1} \rightarrow\left(\mathrm{H}_{\mathrm{l}}^{1}\right)^{*}$ is compact, and hence $\Phi \in \mathrm{C}^{1}\left(\mathrm{H}_{1}^{1}, \mathbb{R}\right)$. Moreover,

$$
\begin{aligned}
\Psi^{\prime}(\mathrm{u}) v & =\int_{0}^{\mathrm{l}}\langle\mathrm{f}(\mathrm{x}, \mathrm{u}), v\rangle, \\
\Phi^{\prime}(\mathrm{u}) v & =\left(\mathrm{u}^{+}, v^{+}\right)-\left(\mathrm{u}^{-}, v^{-}\right)-\Psi^{\prime}(\mathrm{u}) v
\end{aligned}
$$

for all $\mathrm{u}, v \in \mathrm{H}_{\mathrm{l}}^{1}=\mathrm{H}^{-} \oplus \mathrm{H}^{0} \oplus \mathrm{H}^{+}$with $\mathrm{u}=\mathrm{u}^{-}+\mathrm{u}^{0}+\mathrm{u}^{+}$and $v=v^{-}+v^{0}+v^{+}$, respectively, and critical 
points of $\Phi$ on $\mathrm{H}_{l}^{1}$ are solutions of (1.1).

Let $X_{j}=\operatorname{span}\left\{e_{j}\right\}$ for all $j \in \mathbb{N}$, where $\left\{e_{n}: n \in \mathbb{N}\right\}$ is the system of eigenfunctions of $\mathcal{A}$, and $Y_{k}=$ $\bigoplus_{j=1}^{k} X_{j}, Z_{k}=\overline{\bigoplus_{j=k}^{\infty} X_{j}}$. Consider the following $C^{1}$-functional $\Phi_{\lambda}: H_{l}^{1} \rightarrow \mathbb{R}$ defined by

$$
\Phi_{\lambda}:=\mathrm{A}(\mathrm{u})-\lambda \mathrm{B}(\mathrm{u}), \quad \lambda \in[1,2] .
$$

where

$$
A(u)=\frac{1}{2}\left\|u^{+}\right\|^{2}, \quad B(u)=\frac{1}{2}\left\|u^{-}\right\|^{2}+\int_{0}^{l} F(x, u) d x .
$$

By virtue of Proposition 2.5, we know that $\Phi_{\lambda} \in \mathrm{C}^{1}\left(\mathrm{H}_{l}^{1}, \mathbb{R}\right)$ for all $\lambda \in[1,2]$. Note that $\Phi_{1}=\Phi$, where $\Phi$ is the functional defined in (2.19).

Lemma 2.6. Let $\left(\mathrm{AF}_{1}\right)$ and $\left(\mathrm{AF}_{3}\right)$ hold. Then $\mathrm{B}(\mathrm{u}) \geqslant 0$ for all $\mathrm{u} \in \mathrm{H}_{\mathrm{l}}^{1}$ and $\mathrm{B}(\mathrm{u}) \rightarrow \infty$ as $\|\mathrm{u}\| \rightarrow \infty$ on any finite-dimensional subspace of $\mathrm{H}_{l}^{1}$.

Proof. Obviously, $(2.23)$ and $\left(\mathrm{AF}_{1}\right)$ imply that $\mathrm{B}(\mathrm{u}) \geqslant 0$ for all $u \in \mathrm{H}_{\mathrm{l}}^{1}$.

We claim that for any finite-dimensional subspace $E \in H_{l}^{1}$, there exists a constant $\epsilon>0$ such that

$$
\text { meas }(\{x \in[0, l]:|u(x)| \geqslant \epsilon\|u\|\}) \geqslant \epsilon, \quad \forall u \in E \backslash\{0\},
$$

where meas $(\cdot)$ denotes the Lebesgue measure in $\mathbb{R}$.

If this conclusion is not true, then for any $n \in \mathbb{N}$, there exists $u_{n} \in E \backslash\{0\}$ such that

$$
\text { meas }\left(\left\{x \in[0, l]:\left|u_{n}(x)\right| \geqslant \frac{\left\|u_{n}\right\|}{n}\right\}\right)<\frac{1}{n} \text {. }
$$

Set $v_{n}=\frac{u_{n}}{\left\|u_{n}\right\|} \in E$ for all $n \in \mathbb{N}$. Then $\left\{v_{n}\right\}$ is bounded, and

$$
\text { meas }\left(\left\{x \in[0, l]:\left|v_{n}(x)\right| \geqslant \frac{1}{n}\right\}\right)<\frac{1}{n}, \quad \forall n \in \mathbb{N}
$$

Passing to a subsequence if necessary, we may assume $v_{n} \rightarrow v_{0}$ in $\mathrm{H}_{\imath}^{1}$ for some $v_{0} \in \mathrm{E}$. Clearly, $\left\|v_{0}\right\|=1$, and

$$
\int_{0}^{l}\left|v_{n}-v_{0}\right| \mathrm{d} x \rightarrow 0 \quad \text { as } \mathrm{n} \rightarrow \infty, \quad\left\|v_{0}\right\|_{\infty}>0
$$

By the definition of norm $\|\cdot\|_{\infty}$, there exists a positive constant $\delta_{0}$ such that

$$
\operatorname{meas}\left(\left\{x \in[0, l]:\left|v_{0}(x)\right| \geqslant \delta_{0}\right\}\right) \geqslant \delta_{0} .
$$

For any $n \in \mathbb{N}$, set

$$
\Lambda_{n}=\left\{x \in[0, l]:\left|\nu_{n}(x)\right|<\frac{1}{n}\right\}, \quad \Lambda_{n}^{c}=[0, l] \backslash \Lambda_{n} .
$$

Let $\Lambda_{0}=\left\{x \in[0, l]:\left|v_{0}(x)\right| \geqslant \delta_{0}\right\}$. Applying (2.25) and (2.27), for $n$ large enough, one has

$$
\operatorname{meas}\left(\Lambda_{\mathfrak{n}} \cap \Lambda_{0}\right) \geqslant \operatorname{meas}\left(\Lambda_{0}\right)-\operatorname{meas}\left(\Lambda_{n}^{\mathrm{c}}\right) \geqslant \delta_{0}-\frac{1}{n} \geqslant \frac{\delta_{0}}{2}
$$

Evidently, for $n$ large enough, we have

$$
\int_{0}^{l}\left|v_{\mathrm{n}}-v_{0}\right| \mathrm{d} x \geqslant \int_{\Lambda_{\mathrm{n}} \cap \Lambda_{0}}\left(\left|v_{0}\right|-\left|v_{\mathrm{n}}\right|\right) \mathrm{d} x \geqslant\left(\delta_{0}-\frac{1}{\mathrm{n}}\right) \cdot \operatorname{meas}\left(\Lambda_{\mathrm{n}} \cap \Lambda_{0}\right)>0,
$$

which contradicts (2.26). So (2.24) holds. 
For the $\epsilon$ given in (2.24), set $\Lambda_{\mathfrak{u}}=\{x \in[0, l]:|u(x)| \geqslant \epsilon\|u\|\}$ for all $u \in E \backslash\{0\}$. Using (2.24),

$$
\operatorname{meas}\left(\Lambda_{\mathfrak{u}}\right) \geqslant \epsilon, \quad \forall u \in E \backslash\{0\} \text {. }
$$

Applying $\left(\mathrm{AF}_{3}\right)$, there exists a constant $\mathrm{R}_{3}>\mathrm{R}_{1}$ such that

$$
\mathrm{F}(\mathrm{x}, \mathrm{u}) \geqslant \frac{\mathrm{d}}{2}|\mathrm{u}|, \quad \forall x \in[0, \mathrm{l}] \text { and }|\mathrm{u}| \geqslant \mathrm{R}_{3},
$$

where $R_{1}$ is given in $\left(A F_{1}\right)$. Observe that

$$
|u(x)| \geqslant R_{3}, \quad \forall x \in \Lambda_{\mathfrak{u}}
$$

for any $u \in E$ with $\|u\| \geqslant \frac{R_{3}}{\epsilon}$. By $\left(A_{1}\right)$, (2.28)-(2.30), for any $u \in E$ with $\|u\| \geqslant \frac{R_{3}}{\epsilon}$, we obtain

$$
B(u) \geqslant \int_{\Lambda_{u}} F(x, u) d x \geqslant d \epsilon\|u\| \cdot \frac{\operatorname{meas}\left(\Lambda_{\mathfrak{u}}\right)}{2} \geqslant \frac{d \epsilon^{2}}{2}\|u\|,
$$

which implies $\mathrm{B}(\mathrm{u}) \rightarrow \infty$ as $\|\mathrm{u}\| \rightarrow \infty$ on any finite dimensional subspace $\mathrm{E} \subset \mathrm{H}_{\mathrm{l}}^{1}$. The proof of lemma 2.6 is finished.

Lemma 2.7. Assume that $\left(\mathrm{AF}_{1}\right)-\left(\mathrm{AF}_{3}\right)$ is satisfied. Then there exist a positive integer $\mathrm{k}_{1}$ and two sequences $0<\mathrm{r}_{\mathrm{k}}<\rho_{\mathrm{k}} \rightarrow 0$ as $\mathrm{k} \rightarrow \infty$ such that

$$
\begin{aligned}
& \alpha_{k}(\lambda):=\inf _{u \in Z_{k},\|u\|=\rho_{k}} \Phi_{\lambda}(u)>0, \quad \forall k \geqslant k_{1}, \\
& \xi_{k}(\lambda):=\inf _{u \in Z_{k},\|u\| \leqslant \rho_{k}} \Phi_{\lambda}(u) \rightarrow 0 \text { as } k \rightarrow \infty \text { uniformly for } \lambda \in[1,2],
\end{aligned}
$$

and

$$
\beta_{k}(\lambda):=\max _{\mathfrak{u} \in Y_{k},\|u\|=r_{k}} \Phi_{\lambda}(\mathfrak{u})<0, \quad \forall k \in \mathbb{N},
$$

where $Y_{k}=\bigoplus_{j=1}^{k} X_{j}=\operatorname{span}\left\{e_{1}, e_{2}, \cdots, e_{k}\right\}$ and $Z_{k}=\overline{\bigoplus_{j=k}^{\infty} X_{j}}=\overline{\operatorname{span}\left\{e_{k}, \cdots\right\}}$ for all $k \in \mathbb{N}$.

Proof.

Step 1. We show that (2.31) and (2.32) hold.

Note that $Z_{k} \subset H^{+}$for $k$ large enough. Due to (2.1), for any $u \in H_{l}^{1}$ with $\|u\| \leqslant \frac{R_{2}}{\tau_{\infty}}$, one has $\|u\|_{\infty} \leqslant R_{2}$, where $R_{2}$ and $\tau_{\infty}$ are the constants given in $\left(\mathrm{AF}_{2}\right)$ and (2.1), respectively. Then for $k$ large enough and $u \in Z_{k}$ with $\|u\| \leqslant \frac{R_{2}}{\tau_{\infty}}$, by $\left(\mathrm{AF}_{2}\right)$, we obtain

$$
\Phi_{\lambda}(u) \geqslant \frac{1}{2}\|u\|^{2}-2 \int_{0}^{l} F(x, u) d x \geqslant \frac{1}{2}\|u\|^{2}-2 c_{2}\|u\|_{1}, \quad \forall \lambda \in[1,2] .
$$

Let

$$
l_{k}=\sup _{\mathfrak{u} \in Z_{k},\|u\|=1}\|u\|_{1}, \quad \forall k \in \mathbb{N}
$$

then

$$
l_{\mathrm{k}} \rightarrow 0, \text { as } \mathrm{k} \rightarrow \infty
$$

Since $H_{l}^{1}$ is compactly embedded into $L^{1}$. Evidently, (2.34) and (2.35) imply

$$
\Phi_{\lambda}(u) \geqslant \frac{1}{2}\|u\|^{2}-2 c_{2} l_{k}\|u\|
$$


for any $k$ large enough and $u \in Z_{k}$ with $\|u\| \leqslant \frac{R_{2}}{\tau_{\infty}}$. For any $k \in \mathbb{N}$, let

$$
\rho_{\mathrm{k}}=8 \mathrm{c}_{2} l_{\mathrm{k}} \text {. }
$$

Combining this with (2.36), we get

$$
\rho_{\mathrm{k}} \rightarrow 0 \text { as } \mathrm{k} \rightarrow \infty \text {. }
$$

Clearly, there exists a positive integer $k_{1}$ large enough such that

$$
\rho_{\mathrm{k}}<\frac{\mathrm{R}_{2}}{\tau_{\infty}}, \quad \forall \mathrm{k} \geqslant \mathrm{k}_{1}
$$

Using (2.37), (2.38), and (2.40), for any $k \geqslant k_{1}$

$$
\alpha_{k}(\lambda):=\inf _{u \in Z_{k},\|u\|=\rho_{k}} \Phi_{\lambda}(u) \geqslant \frac{\rho_{k}^{2}}{4}>0 .
$$

By (2.37), for any $k \geqslant k_{1}$ and $u \in Z_{k}$ with $\|u\| \leqslant \rho_{k}$, we have

$$
\Phi_{\lambda}(u) \geqslant-2 c_{2} l_{k} \rho_{k} .
$$

Note that $\Phi_{\lambda}(0)=0$, then

$$
0 \geqslant \inf _{u \in Z_{k},\|u\| \leqslant \rho_{k}} \Phi_{\lambda}(u) \geqslant-2 c_{2} l_{k} \rho_{k}, \quad \forall k \geqslant k_{1} .
$$

Combining this with (2.36) and (2.39), we have

$$
\xi_{k}(\lambda):=\inf _{\mathfrak{u} \in Z_{k},\|u\| \leqslant \rho_{k}} \Phi_{\lambda}(u) \rightarrow 0 \text { as } k \rightarrow \infty \text { uniformly for } \lambda \in[1,2] .
$$

Step 2. We prove (2.33).

For any $k \in \mathbb{N}$, there exists a constant $C_{k}>0$ such that

$$
\|\mathrm{u}\|_{2} \geqslant \mathrm{C}_{\mathrm{k}}\|\mathrm{u}\|, \quad \forall \mathrm{u} \in \mathrm{Y}_{\mathrm{k}} .
$$

Using $\left(\mathrm{AF}_{2}\right)$, for any $k \in \mathbb{N}$, there exists a constant $\delta_{k}>0$ such that

$$
\mathrm{F}(\mathrm{x}, \mathrm{u}) \geqslant \frac{1}{\mathrm{C}_{\mathrm{k}}^{2}}|\mathrm{u}|^{2}, \quad \forall|\mathrm{u}| \leqslant \delta_{\mathrm{k}}
$$

By (2.1), for any $k \in \mathbb{N}$ and $u \in H_{l}^{1}$ with $\|u\| \leqslant \frac{\delta_{k}}{\tau_{\infty}}$, one has $\|u\|_{\infty} \leqslant \delta_{k}$, where $\tau_{\infty}$ is the constant in (2.1). Applying (2.41) and (2.42), for any $k \in \mathbb{N}$ and $u \in Y_{k}$ with $\|u\| \leqslant \frac{\delta_{k}}{\tau_{\infty}}$, one has

$$
\Phi_{\lambda}(u) \leqslant \frac{1}{2}\|u\|^{2}-\frac{\|u\|_{2}^{2}}{C_{k}^{2}} \leqslant-\frac{1}{2}\|u\|^{2}, \quad \forall \lambda \in[1,2] .
$$

Now for any $k \in \mathbb{N}$, we choose $0<r_{k}<\min \left\{\rho_{k}, \frac{\delta_{k}}{\tau_{\infty}}\right\}$, thus

$$
\beta_{k}(\lambda):=\max _{u \in Y_{k},\|u\|=r_{k}} \Phi_{\lambda}(u) \leqslant-\frac{r_{k}^{2}}{2}<0, \quad \forall k \in \mathbb{N} .
$$

The proof of this lemma is finished.

Proof of Theorem 1.6. By virtue of (2.20) and (2.1), $\Phi_{\lambda}$ maps bounded sets to bounded sets uniformly for $\lambda \in[1,2]$. Obviously, $\Phi_{\lambda}(-\mathfrak{u})=\Phi_{\lambda}(u)$ for all $(\lambda, u) \in[1,2] \times H_{l}^{1}$ since $F(x,-u)=F(x, u)$. So, the condition $\left(T_{1}\right)$ of the variant fountain theorem (see [26]) holds. Lemma 2.6 indicates that the condition $\left(T_{2}\right)$ is 
satisfied, and Lemma 2.7 implies that $\left(T_{3}\right)$ holds for all $k \geqslant k_{1}$, where $k_{1}$ is given in (2.42). Hence, by virtue of the variant fountain theorem, for any $k \geqslant k_{1}$, there exist $\lambda_{n} \rightarrow 1, u_{\lambda_{n}} \in Y_{n}$ such that

$$
\Phi_{\lambda_{n}}^{\prime} \mid \gamma_{n}\left(u_{\lambda_{n}}\right)=0, \quad \Phi_{\lambda_{n}}\left(u_{\lambda_{n}}\right) \rightarrow \eta_{k} \in\left[\xi_{k}(2), \beta_{k}(1)\right] \text { as } n \rightarrow \infty .
$$

For the sake of notational simplicity, throughout the remaining proof of Theorem 1.6 we always set $u_{n}=u_{\lambda_{n}}$ for all $n \in \mathbb{N}$.

Claim 1. $\left\{u_{n}\right\}$ is bounded in $H_{l}^{1}$.

Obviously, for the constant $R_{3}$ given in (2.29), there exists a constant $M_{3}$ such that

$$
\left|F(x, u)-\frac{1}{2}\langle f(x, u), u\rangle\right| \leqslant M_{3}, \forall x \in[0, l] \text { and }|u| \leqslant R_{3} .
$$

By virtue of (2.21), (2.22), (2.29), (2.44), (2.45), and $\left(\mathrm{AF}_{1}\right)$, we obtain

$$
\begin{aligned}
-\Phi_{\lambda_{n}}\left(u_{n}\right) & =\frac{1}{2} \Phi_{\lambda_{n}}^{\prime} \mid Y_{n}\left(u_{n}\right) u_{n}-\Phi_{\lambda_{n}}\left(u_{n}\right) \\
& =\lambda_{n} \int_{0}^{l}\left[F\left(x, u_{n}\right)-\frac{1}{2}\left\langle f\left(x, u_{n}\right), u_{n}\right\rangle\right] d x \\
& \geqslant \frac{\lambda_{n}(2-\mu)}{2} \int_{L_{n}} F\left(x, u_{n}\right) d x-\lambda_{n} M_{3} l \\
& \geqslant \frac{d \lambda_{n}(2-\mu)}{4} \int_{L_{n}}\left|u_{n}\right| d x-\lambda_{n} M_{3} l, \quad \forall n \in \mathbb{N},
\end{aligned}
$$

where $L_{n}=\left\{x \in[0, l]:\left|u_{n}(x)\right| \geqslant R_{3}\right\}$. Combining this with (2.44), there exists a positive constant $M_{4}$ such that

$$
\int_{L_{n}}\left|u_{n}\right| d x \leqslant M_{4}, \quad \forall n \in \mathbb{N}
$$

For any $n \in \mathbb{N}$, let $\chi_{n}:[0, l] \rightarrow \mathbb{R}$ be the indicator of $L_{n}$, that is for all $n \in \mathbb{N}$,

$$
\chi_{n}(x)= \begin{cases}1, & x \in L_{n}, \\ 0, & x \notin L_{n} .\end{cases}
$$

Then by the definition of $L_{n}$ and (2.46), one has

$$
\left\|\left(1-\chi_{n}\right) u_{n}\right\|_{\infty} \leqslant R_{3} \text { and }\left\|\chi_{n} u_{n}\right\|_{1} \leqslant M_{4}, \forall n \in \mathbb{N} .
$$

Applying (2.1) and by Hölder inequality, we have

$$
\begin{aligned}
\left\|u_{n}^{-}+u_{n}^{0}\right\|_{2} & \leqslant\left\|\left(1-\chi_{n}\right) u_{n}\right\|_{\infty}\left\|u_{n}^{-}+u_{n}^{0}\right\|_{1}+\left\|x_{n} u_{n}\right\|_{1}\left\|u_{n}^{-}+u_{n}^{0}\right\|_{\infty} \\
& \leqslant c_{3}\left(R_{3}+M_{4}\right)\left\|u_{n}^{-}+u_{n}^{0}\right\|_{2}, \quad \forall n \in \mathbb{N}
\end{aligned}
$$

for some $c_{3}>0$. Thus, we obtain

$$
\left\|u_{n}^{-}+u_{n}^{0}\right\|_{2} \leqslant c_{3}\left(R_{3}+M_{4}\right), \quad \forall n \in \mathbb{N} .
$$

In view of the equivalence of norms $\|\cdot\|$ and $\|\cdot\|_{2}$ on $H^{-} \bigoplus H^{0}$, there exists a positive constant $M_{5}$ such that

$$
\left\|u_{n}^{-}+u_{n}^{0}\right\| \leqslant M_{5}, \quad \forall n \in \mathbb{N} .
$$

Note that

$$
\left\|u_{n}^{+}\right\|^{2}=2 \Phi_{\lambda_{n}}\left(u_{n}\right)+\lambda_{n}\left\|u_{n}^{-}\right\|^{2}+2 \lambda_{n} \int_{0}^{l} F\left(x, u_{n}\right) d x, \quad \forall n \in \mathbb{N}
$$


Thus by (2.19), (2.20), (2.43), and (2.47), it holds that

$$
\begin{aligned}
\left\|u_{n}\right\|^{2} & =2 \Phi_{\lambda_{n}}\left(u_{n}\right)+\lambda_{n}\left\|u_{n}^{-}\right\|^{2}+\left\|u_{n}^{-}+u_{n}^{0}\right\|^{2}+2 \lambda_{n} \int_{0}^{l} F\left(x, u_{n}\right) d x \\
& \leqslant M_{6}+4 C_{1} \tau_{\mu}^{\mu}\left\|u_{n}\right\|_{\mu}^{\mu}, \forall n \in \mathbb{N}
\end{aligned}
$$

for some $M_{6}>0$, where $\tau_{\mu}$ and $C_{1}$ are the constants in (2.1) and (2.20), respectively. Since $\mu<2$ in (2.48), $\left\{u_{n}\right\}$ is bounded in $H_{l}^{1}$.

Claim 2. $\left\{u_{n}\right\}$ possesses a strong convergent subsequence in $H_{l}^{1}$.

Actually, by Claim 1, without loss of generality, we can assume that

$$
u_{n}^{-} \rightarrow u_{0}^{-}, u_{n}^{0} \rightarrow u_{0}^{0}, u_{n}^{+} \rightarrow u_{0}^{+}, u_{n} \rightarrow u_{0}, \text { as } n \rightarrow \infty
$$

for some $\mathrm{u}_{0}=\mathrm{u}_{0}^{-}+\mathrm{u}_{0}^{0}+\mathrm{u}_{0}^{+} \in \mathrm{H}_{\mathrm{l}}^{1}=\mathrm{H}^{-} \oplus \mathrm{H}^{0} \oplus \mathrm{H}^{+}$since $\operatorname{dim}\left(\mathrm{H}^{-} \oplus \mathrm{H}^{0}\right)<\infty$. In view of the Riesz representation theorem, $\left.\Phi_{\lambda_{n}}^{\prime}\right|_{\gamma_{n}}: Y_{n} \rightarrow Y_{n}^{*}$ and $\Psi^{\prime}: H_{l}^{1} \rightarrow\left(H_{l}^{1}\right)^{*}$ can be considered as $\left.\Phi_{\lambda_{n}}^{\prime}\right|_{\gamma_{n}}: Y_{n} \rightarrow Y_{n}$ and $\Psi^{\prime}: H_{l}^{1} \rightarrow H_{l}^{1}$, respectively, where $Y_{n}^{*}$ is the dual space of $Y_{n}$. Note that

$$
0=\Phi_{\lambda_{n}}^{\prime} \mid Y_{n}\left(u_{n}\right)=u_{n}^{+}-\lambda_{n}\left(u_{n}^{-}+P_{n} \Psi^{\prime}\left(u_{n}\right)\right), \quad \forall n \in \mathbb{N},
$$

where $P_{n}: H_{l}^{1} \rightarrow Y_{n}$ is the orthogonal projection for all $n \in \mathbb{N}$. Thus

$$
u_{n}^{+}=\lambda_{n}\left(u_{n}^{-}+P_{n} \Psi^{\prime}\left(u_{n}\right)\right), \quad \forall n \in \mathbb{N} .
$$

By Proposition 2.5, $\Psi^{\prime}: \mathrm{H}_{l}^{1} \rightarrow \mathrm{H}_{\mathrm{l}}^{1}$ is also compact. Since the compactness of $\Psi^{\prime}$ and (2.50), the right hand side of (2.50) converges strongly in $\mathrm{H}_{l}^{1}$ and $\mathrm{u}_{n}^{+} \rightarrow \mathrm{u}_{0}^{+}$in $\mathrm{H}_{l}^{1}$. Combining this with (2.49), we obtain $u_{n} \rightarrow u_{0}$ in $H_{l}^{1}$. Hence Claim 2 is true.

Now by the variant fountain theorem (see $[1,10,26]$ ), we know that $\Phi=\Phi_{1}$ has infinitely many nonzero critical points. Thus, problem (1.1) has infinitely many nonzero solutions due to Proposition 2.5. The proof of Theorem 1.6 is finished.

\subsection{Subharmonic solutions of elliptic equation}

In this section, we assume $p(x)=m^{2} \omega^{2}$, where $m \in \mathbb{N}, \omega=\frac{2 \pi}{l}$. Choose $k \in \mathbb{N}$. Replacing $l$ by $\mathrm{kl}$ in the definitions of $\mathrm{H}_{l}^{1}, \Phi, \Phi^{\prime}, \mathrm{Q}, \mathrm{H}^{0}, \mathrm{H}^{-}$, and $\mathrm{H}^{+}$, we get the corresponding spaces and functions $\mathrm{H}_{\mathrm{k} l}^{1}, \Phi_{\mathrm{k}}, \Phi_{\mathrm{k}}^{\prime}, \mathrm{Q}_{\mathrm{k}}, \mathrm{H}_{\mathrm{k}}^{0}, \mathrm{H}_{\mathrm{k}}^{-}$, and $\mathrm{H}_{\mathrm{k}}^{+}$, respectively. Especially, according to $\mathrm{p}(\mathrm{x})=\mathrm{m}^{2} \mathrm{w}^{2}$, we get

$$
\begin{aligned}
& H_{k}^{-}=\left\{\sum_{j=0}^{k m-1}\left(a_{j} \cos j k^{-1} \omega x+b_{j} \sin j k^{-1} \omega x\right): a_{j}, b_{j} \in \mathbb{R}, 0 \leqslant j \leqslant k m-1\right\}, \\
& H_{k}^{0}=\{a \cos m \omega x+b \sin m \omega x: a, b \in \mathbb{R}\}, \\
& H_{k}^{+}=\left\{u \in H_{k l}^{1}: \int_{0}^{k l} u(x) \cos j k^{-1} \omega x d x=\int_{0}^{k l} u(x) \sin j k^{-1} \omega x d x=0,0 \leqslant j \leqslant k m\right\},
\end{aligned}
$$

and we define $\mathrm{H}_{\mathrm{k}}^{-}=\emptyset$ if $\mathrm{m}=0$. Let us point out that the norm $\|\cdot\|$ in the following is the usual norm defined on $\mathrm{H}_{\mathrm{kl}}^{1}$. Arguing as Section 2.1, we can find $\delta_{k}>0$ and $\mathrm{C}_{\mathrm{k}}>0$ such that

$$
\begin{aligned}
& \mathrm{Q}_{\mathrm{k}} \leqslant-\frac{\delta_{\mathrm{k}}}{2}\|\mathrm{u}\|^{2}, \quad \text { if } \mathrm{u} \in \mathrm{H}_{\mathrm{k}}^{-}, \\
& \mathrm{Q}_{\mathrm{k}} \geqslant \frac{\delta_{\mathrm{k}}}{2}\|\mathrm{u}\|^{2}, \quad \text { if } \mathrm{u} \in \mathrm{H}_{\mathrm{k}}^{+},
\end{aligned}
$$

and

$$
\|\mathrm{u}\|_{\infty} \leqslant \mathrm{C}_{\mathrm{k}}\|\mathrm{u}\|, \quad \forall \mathrm{u} \in \mathrm{H}_{\mathrm{kl}}^{1} .
$$


Proof of Theorem 1.7.

Step 1 . In a similar way as the proof of Lemma 2.3 with $l$ replaced by $k l$, we can obtain that $\Phi_{k}$ satisfies the $(\mathrm{C})$ condition.

Step 2. We claim that there exist $\rho_{k}>0$ and $b_{k}>0$ such that

$$
\Phi_{k}(u) \geqslant b_{k}>0, \quad \forall u \in H_{k}^{+} \cap \partial B_{\rho_{k}} .
$$

Evidently, by virtue of $\left(\mathrm{HF}_{1}\right)$ and the periodicity of $\mathrm{F}$ in $x$, for any $\varepsilon>0$, there exists a positive constant $\rho_{1}$ such that

$$
|\mathrm{F}(\mathrm{x}, \mathrm{u})| \leqslant \varepsilon_{\mathrm{k}}|\mathrm{u}|^{2}
$$

for all $|u| \leqslant \rho_{1}$ and a.e. $x \in[0, l]$. Let $\varepsilon_{k}=\frac{\delta_{k}}{4}>0, \rho_{k}=\min \left\{1, \frac{\rho_{1}}{C_{k}}\right\}>0$, and $b_{k}=\frac{\delta_{k}}{4} \rho_{k}^{2}>0$, using (2.52)-(2.54), we obtain

$$
\Phi_{k}(u) \geqslant \frac{\delta_{k}}{2}\|u\|^{2}-\varepsilon_{k} \int_{0}^{k l}|u|^{2} d x \geqslant \frac{\delta_{k}}{4}\|u\|^{2}=b_{k}
$$

for all $u \in \mathrm{H}_{\mathrm{k}}^{+} \cap \partial \mathrm{B}_{\rho_{\mathrm{k}}}$.

Step 3. Let

$$
e_{k}(x)=\sin \left((k m+1) k^{-1} \omega x\right) u_{0}
$$

for all $x \in \mathbb{R}$ and $u_{0} \in \mathbb{R}$ with $\left|u_{0}\right|=1$, where $\omega=\frac{2 \pi}{l}$. Then, one has

$$
e_{k}^{\prime}=\frac{k m+1}{k} \omega \cos \left((k m+1) k^{-1} \omega x\right) u_{0}
$$

for all $x \in \mathbb{R}$, which implies

$$
\left\|e_{k}\right\|_{L^{2}(0, k l ; \mathbb{R})}^{2}=\frac{k l}{2}
$$

and

$$
\left\|e_{k}^{\prime}\right\|_{L^{2}(0, k l ; R)}^{2}=\frac{(k m+1)^{2}}{k^{2}} \omega^{2}\left\|e_{k}\right\|_{L^{2}(0, k l ; R)}^{2} .
$$

Applying $\left(\mathrm{HF}_{4}\right)$, for

$$
\varepsilon_{0}=\inf _{x \in[0, l]} \liminf _{|u| \rightarrow \infty} \frac{F(x, u)}{|u|^{2}}-\frac{1+2 m}{2} \omega^{2}>0,
$$

there exists a positive constant $l_{4}$ such that

$$
F(x, u) \geqslant\left(\frac{1+2 m}{2} \omega^{2}+\varepsilon_{0}\right)|u|^{2}
$$

for all $|u| \geqslant l_{4}$ and a.e. $x \in[0, l]$. Therefore, due to $\left(\mathrm{HF}_{3}\right)$ and the periodicity of $F(\cdot, u)$, we have

$$
\mathrm{F}(\mathrm{x}, \mathrm{u}) \geqslant\left(\frac{1+2 \mathrm{~m}}{2} \omega^{2}+\varepsilon_{0}\right)|\mathrm{u}|^{2}-\mathrm{M}_{7}
$$

for all $u \in \mathbb{N}$ and a.e. $x \in[0, k l]$, where $M_{7}=\left(\frac{1+2 m}{2} \omega^{2}+\varepsilon_{0}\right) l_{4}^{2}$.

By the properties of $\mathrm{H}_{\mathrm{k}}^{-}$and $\mathrm{H}_{\mathrm{k}}^{0}$, one has

$$
\|\mathfrak{u}\|^{2}=\int_{0}^{k l}|\mathfrak{u}|^{2} \mathrm{~d} x+\int_{0}^{k l}\left|\mathrm{u}^{\prime}\right|^{2} \mathrm{~d} x \leqslant\left(1+\mathrm{m}^{2} \mathrm{w}^{2}\right)\|\mathrm{u}\|_{\mathrm{L}^{2}}^{2}
$$

for all $u \in H_{k}^{-} \bigoplus H_{k}^{0}$. Thus, combining (2.51) and (2.55) with (2.56), we get

$$
\Phi_{k}\left(s e_{k}+u\right) \leqslant-\frac{\delta_{k}}{2}\left\|u^{-}\right\|^{2}+\frac{s^{2}}{2} \int_{0}^{k l}\left|e_{k}^{\prime}\right|^{2} d x-\frac{m^{2} w^{2} s^{2}}{2} \int_{0}^{k l}\left|e_{k}\right|^{2} d x-\int_{0}^{k l} F\left(x, s e_{k}+u\right) d x
$$




$$
\begin{aligned}
& \leqslant \frac{1}{2} \omega^{2} s^{2}\left(\frac{1+2 k m}{k^{2}}\right)\left\|e_{k}\right\|_{L^{2}}^{2}-\left(\frac{1+2 m}{2} \omega^{2}+\varepsilon_{0}\right)\left(s^{2}\left\|e_{k}\right\|_{L^{2}}^{2}+\|u\|_{L^{2}}^{2}\right)+k M_{7} l \\
& \leqslant-\frac{1}{2} \varepsilon_{0} k l s^{2}-M_{8}\|u\|^{2}+k M_{7} l
\end{aligned}
$$

for all $s>0$ and $u \in H_{k}^{-} \bigoplus H_{k}^{0}$, where $M_{8}=\left((1+2 m) w^{2} / 2+\varepsilon_{0}\right) /\left(1+m^{2} w^{2}\right)$.

Hence we have

$$
\Phi_{k}\left(s e_{k}+u\right) \leqslant 0, \text { either } s \geqslant s_{1} \text { or }\|u\| \geqslant s_{2},
$$

where

$$
s_{1}=\sqrt{\frac{2 M_{7}}{\varepsilon_{0}}} \text { and } s_{2}=\sqrt{\frac{k M_{7} l}{M_{8}}}
$$

Let

$$
F_{k}=\left\{s e_{k}: 0 \leqslant s \leqslant s_{1}\right\} \bigoplus\left\{u \in H_{k}^{-} \bigoplus H_{k}^{0}:\|u\| \leqslant s_{2}\right\}
$$

Thus

where

$$
\partial F_{k}=F_{k_{1}} \cup F_{k_{2}} \cup F_{k_{3}} \text {, }
$$

$$
\begin{aligned}
& \mathrm{F}_{\mathrm{k}_{1}}=\left\{\mathrm{u} \in \mathrm{H}_{\mathrm{k}}^{-} \bigoplus \mathrm{H}_{\mathrm{k}}^{0}:\|\mathrm{u}\| \leqslant \mathrm{s}_{2}\right\}, \\
& \mathrm{F}_{\mathrm{k}_{2}}=\mathrm{s}_{1} e_{\mathrm{k}} \bigoplus\left\{\mathrm{u} \in \mathrm{H}_{\mathrm{k}}^{-} \bigoplus \mathrm{H}_{\mathrm{k}}^{0}:\|\mathrm{u}\| \leqslant s_{2}\right\}, \\
& \mathrm{F}_{\mathrm{k}_{3}}=\left\{\mathrm{se}_{\mathrm{k}}: 0 \leqslant \mathrm{~s} \leqslant \mathrm{~s}_{1}\right\} \bigoplus\left\{\mathrm{u} \in \mathrm{H}_{\mathrm{k}}^{-} \bigoplus \mathrm{H}_{\mathrm{k}}^{0}:\|\mathrm{u}\|=\mathrm{s}_{2}\right\} .
\end{aligned}
$$

By virtue of (2.57), one has

$$
\Phi_{\mathrm{k}}(\mathrm{u}) \leqslant 0, \quad \forall \mathrm{u} \in \mathrm{F}_{\mathrm{k}_{2}} \cup \mathrm{F}_{\mathrm{k}_{3}} .
$$

Applying $\left(\mathrm{HF}_{3}\right)$, it holds that $\Phi_{\mathrm{k}}(\mathrm{u}) \leqslant 0$ for all $u \in \mathrm{H}_{\mathrm{k}}^{-} \bigoplus \mathrm{H}_{\mathrm{k}}^{0}$, which implies that

$$
\Phi_{k}(u) \leqslant 0, \quad \forall u \in F_{k_{1}} .
$$

Therefore,

$$
\Phi_{k}(u) \leqslant 0, \quad \forall u \in \partial F_{k} .
$$

Finally, by the generalized mountain pass theorem (see $[11,14,17,18,27]$ ), for a given $k \in \mathbb{N}$, there exists a critical point $u_{k} \in H_{k l}^{1}$ such that $\Phi_{k}\left(u_{k}\right)>0$.

Step 4. We claim that (1.1) has infinitely many subharmonic solutions.

If $u_{k}=u_{1}$ for some $k>1$, it is easy to see that

$$
\Phi_{k}\left(u_{k}\right)=k \Phi_{1}\left(u_{1}\right) \rightarrow+\infty, \text { as } k \rightarrow \infty .
$$

Note that

$$
\Phi_{k}\left(u_{k}\right) \leqslant \sup _{u \in F_{k}}\left(\frac{s^{2}}{2} \int_{0}^{k l}\left|e_{k}^{\prime}\right|^{2} d x-\frac{m^{2} \omega^{2} s^{2}}{2} \int_{0}^{k l}\left|e_{k}\right|^{2} d x-\int_{0}^{k l} F(x, u) d x\right) \leqslant\left(\frac{1+2 m}{2 \varepsilon_{0}}\right) \omega^{2} M_{3} l,
$$

where $F_{k}$ is the same as (2.58). This is a contradiction to (2.59). Hence, $\Phi_{k}\left(u_{k}\right)$ is bounded for all $k$ and there exists a constant $k_{1} \in \mathbb{N}$ such that $u_{k} \neq u_{1}$ for all $k \geqslant k_{1}$. Repeating what we have just shown, there exists a $k_{2}>k_{1}$ such that $u_{k_{1} k} \neq u_{k_{1}}$ for all $k_{1} k \geqslant k_{2}$. If it is not true, then $\Phi_{k_{1} k}\left(u_{k_{1} k}\right)=k \Phi_{k_{1}}\left(u_{k_{1}}\right) \rightarrow \infty$ as $k \rightarrow \infty$, which contradicts that $\Phi_{k_{1} k}\left(u_{k_{1} k}\right)$ is bounded. In a similar way, we can get a sequence $\left\{u_{k_{j}}\right\}$ of distinct nontrivial solutions of problem (1.1). The proof of Theorem 1.7 is finished.

\section{Acknowledgment}

This work was supported financially by the National Natural Science Foundation of China (11471187, 11571197). The authors thank the editor and the referees for careful reading and efforts to this paper. 


\section{References}

[1] Y.-H. Ding, X.-Y. Liu, Periodic solutions of a Dirac equation with concave and convex nonlinearities, J. Differential Equations, 258 (2015), 3567-3588. 1, 2.1 .3

[2] R. Hakl, M. Zamora, Periodic solutions to second-order indefinite singular equations, J. Differential Equations, 263 (2017), 451-469. 1

[3] R. Kajikiya, A critical point theorem related to the symmetric mountain pass lemma and its applications to elliptic equations, J. Funct. Anal., 225 (2005), 352-370. 1.5, 2.1.2

[4] C. Li, R. P. Agarwal, D. Paşca, Infinitely many periodic solutions for a class of new superquadratic second-order Hamiltonian systems, Appl. Math. Lett., 64 (2017), 113-118. 1, 1, 1, 2.1.1, 2.1 .1

[5] L. Li, M. Schechter, Existence solutions for second order Hamiltonian systems, Nonlinear Anal. Real World Appl., 27 (2016), 283-296. 1, 2.1, 2.1.1, 2.2, 2.4

[6] J. Liu, Z.-Q. Zhao, An application of variational methods to second-order impulsive differential equation with derivative dependence, Electron. J. Differential Equations, 2014 (2014), 13 pages. 2.1.1

[7] J. Liu, Z.-Q. Zhao, Multiple solutions for impulsive problems with non-autonomous perturbations, Appl. Math. Lett., 64 (2017), 143-149. 1, 2.1.1

[8] R.-Y. Ma, Nonlinear periodic boundary value problems with sign-changing Green's function, Nonlinear Anal., 74 (2011), 1714-1720. 1

[9] A.-M. Mao, S.-X. Luan, Critical points theorems concerning strongly indefinite functionals and infinite many periodic solutions for a class of Hamiltonian systems, Appl. Math. Comput., 214 (2009), 187-200. 1

[10] A.-M. Mao, L.-J. Yang, A.-X. Qian, S.-X. Luan, Existence and concentration of solutions of Schrdinger-Poisson system, Appl. Math. Lett., 68 (2017), 8-12. 2.1.1, 2.1.3

[11] A.-M. Mao, Y. Zhu, S.-X. Luan, Existence of solutions of elliptic boundary value problems with mixed type nonlinearities, Bound. Value Probl., 2012 (2012), 11 pages. 2.4, 2.2

[12] J. Mawhin, M. Willem, Critical point theory and Hamiltonian systems, Applied Mathematical Sciences, SpringerVerlag, New York, (1989). 2.1, 2.3

[13] J. Pipan, M. Schechter, Non-autonomous second order Hamiltonian systems, J. Differential Equations, 257 (2014), $351-$ 373. 1

[14] A.-X. Qian, Infinitely many sign-changing solutions for a Schrdinger equation, Adv. Difference Equ., 2011 (2011), 6 pages. 2.1.1, 2.2

[15] A.-X. Qian, Sign-changing solutions for some nonlinear problems with strong resonance, Bound. Value Probl., 2011 (2011), 9 pages. 2.2, 2.1.1

[16] P. H. Rabinowitz, Minimax methods in critical point theory with applications to differential equations, CBMS Regional Conference Series in Mathematics, Published for the Conference Board of the Mathematical Sciences, Washington, DC; by the American Mathematical Society, Providence, RI, (1986). 2.1, 2.1.1

[17] M. Schechter, Linking methods in critical point theory, Birkhäuser Boston, Inc., Boston, MA, (1999). 2.2, 2.1.1, 2.2

[18] M. Schechter, Minimax systems and critical point theory, Birkhäuser Boston, Inc., Boston, MA, (2009). 2.2

[19] C.-L. Tang, X.-P. Wu, Periodic solutions for a class of new superquadratic second order Hamiltonian systems, Appl. Math. Lett., 34 (2014), 65-71. 1, 2.1

[20] A. J. Ureña, Periodic solutions of singular equations, Topol. Methods Nonlinear Anal., 47 (2016), 55-72. 1

[21] Y.-Q. Wang, L.-S. Liu, Y.-H. Wu, Positive solutions for a class of fractional boundary value problem with changing sign nonlinearity, Nonlinear Anal., 74 (2011), 6434-6441. 1

[22] Y.-W. Ye, C.-L. Tang, Periodic and subharmonic solutions for a class of superquadratic second order Hamiltonian systems, Nonlinear Anal., 71 (2009), 2298-2307. 1, 1.8

[23] Y.-W. Ye, C.-L. Tang, Infinitely many periodic solutions of non-autonomous second-order Hamiltonian systems, Proc. Roy. Soc. Edinburgh Sect. A, 144 (2014), 205-223.

[24] Q.-Y. Zhang, C.-G. Liu, Infinitely many periodic solutions for second order Hamiltonian systems, J. Differential Equations, 251 (2011), 816-833. 1, 2.5

[25] X.-G. Zhang, L.-S. Liu, Y.-H. Wu, Variational structure and multiple solutions for a fractional advection-dispersion equation, Comput. Math. Appl., 68 (2014), 1794-1805. 2.1.1

[26] W.-M. Zou, Variant fountain theorems and their applications, Manuscripta Math., 104 (2001), 343-358. 2.1.3, 2.1.3

[27] W.-M. Zou, M. Schechter, Critical point theory and its applications, Springer, New York, (2006). 2.1, 2.1.1, 2.1.1, 2.2 